\title{
Caracteristici dendrometrice ale populației de zâmbru de pe versantul nordic al Munțiilor Călimani
}

\author{
C.-C. Rogojan, B. Bîrlădeanu, I. Filimon, I. Popa
}

\begin{abstract}
Rogojanu C.-C., Bîrlădeanu, B., Filimon I., Popa I. 2020. Dendrometric characteristics of the stone pine population on the northern slope of the Călimani Mountains. Bucov. For. 20(1): 33-40.

Abstract. In this study we present biometric and qualitative information concerning the stone pine population from northern slope of Călimani Mts. based on full stone pine trees inventory from 90 ha. Diameter distribution of stone pine trees follow a typical distribution for even-age stands, with left side asymmetry and a mean diameter of $37.2 \pm 17.1 \mathrm{~cm}$. The maximum diameter found in our inventory is 156 $\mathrm{cm}$, been the larger reported for Eastern Carpathians. Regarding the type of damages observed, most of them are represented by closed or open wounds (14.1\%). According with the location of the damages over $85 \%$ of them are at the base of the stem. Woodpecker holes, as a high biodiversity indicator, were found at 79 trees $(2.7 \%)$. In general, our inventory shows that the stone pine population from the northern slope of Călimani Mts. has a very good health status, ensuring the premises for a sustainable dynamic of this population.
\end{abstract}

Keywords: stone pine, diameter distribution, type of damage, Călimani National Park.

Authors. Claudiu-Cosmin Rogojan - Călimani National Park Administration, Saru Dornei, No. 54C, 727515, Suceava, Romania and "Ștefan cel Mare" University of Suceava, Forestry Faculty, Universității Street 13, 720229, Suceava, Romania; Basarab Bârlădeanu, Iosif Filimon - Călimani National Park Administration, Saru Dornei, No. 54C, 727515, Suceava, Romania; Ionel Popa (popaicas@gmail. com) - "Marin Drăcea" National Research-Development Institute in Forestry, Station Câmpulung Moldovenesc, 73bis, Calea Bucovinei, 725100 Câmpulung Moldovenesc, Romania and Center of Mountain Economy -INCE - CE-MONT Vatra Dornei, Petreni street no 49,725700 Vatra Dornei, Romania.

Manuscript received Iulie 01, 2020; revised August 30, 2020; accepted August 30, 2020; online first September 1, 2020.

\section{Introducere}

Zâmbrul (Pinus cembra L.) reprezintă un relict glaciar cu importanță deosebită în stabilitatea ecologică a ecosistemelor forestiere de limită altitudinală superioară din Europa, arealul de distribuţie a speciei cuprinzând zona munților Alpi și Carpaţi (Ulber et al. 2004). Vegetând într-o zonă sensibilă, zâmbrul reprezintă o specie de interes deosebit în evaluarea impactului și adaptării la schimbările climatice și de mediu. Distribuția și structura populaţiilor actuale de zâmbru sunt rezultatul acțiunii puternice a factorului uman, mai ales în zona Munților Alpi (Motta et al. 2006).

Distribuția zâmbrului este limitată la zona 
montană superioară fiind prezent în Alpi între 1500 şi 2000 m, cu exemplare izolate până la 2500 m, iar în România îl întâlnim între 1350 m și 1880 m în Carpații Orientali, respectiv până la 1986 m în Carpații Meridionali, cu o distribuție mozaicată (Blada 1997, Ulber et al., 2004).

În Munții Călimani majoritatea populației de zâmbru este localizată pe versantul nordic, în zona Izvorul Călimani, Pietrosul Călimani, Negoiul Unguresc și mai ales în căldarea Răchitiș (Blada 2008, Kern și Popa 2008). Populaţia de zâmbru de pe versantul nordic al Munților Călimani a fost estimată la peste 7000 de exemplare la nivelul anului 1973 (Seghedin 1983). De asemenea, exemplare izolate de zâmbru se întâlnesc şi pe versantul sudic al Munților Călimani, în zona obârșia pârâului Ilva, populația fiind estimată la peste 270 de exemplare (Gubesh 1971, Abran 2000).

Având în vedere sensibilitatea speciei la variaţia condițiilor climatice şi longevitatea acesteia cu vârste de peste 700 de ani (Popa 2007), zâmbrul a făcut obiectul numeroaselor studii dendroclimatologice și de reconstituire a regimului termic din ultimul mileniu (Popa şi Kern 2009, Popa şi Bouriaud 2014, Nagavciuc et al. 2020). Temperaturile din timpul sezonului de vegetație (mai-iulie) coroborate cu cele din toamna precedentă reprezintă factori determinanți ai proceselor de creștere radială în cazul zâmbrului (Oberhuber 2004, Carrer et al., 2007, Popa și Kern 2009).

Dinamica structurii ecosistemelor forestiere de la limita altitudinală superioară a pădurii, precum şi variațiile spaţiale ale zonelor de tranziţie între pădurea compactă și rariștile dominate de jneapăn și ienupăr reprezintă elemente cheie în înțelegerea impactului schimbărilor climatice și antropice asupra acestor sisteme biologice complexe (Cenuşă 1996, Motta și Nola 2001, Popa și Popa 2007, Popa et al. 2017). Numeroase studii privind structura arboretelor de limită cu zâmbru sunt limitate la investigații pe suprafețe permanente de maxim 1-4 ha (Cenușă 1996, Carrer și Urbinati 2001, Sidor et al. 2013, Vlad et al. 2013, Popa et al. 2017, Carrer et al. 2013, Lingua et al. 34
2008, Beloiu și Beierkuhnlein 2019), neexistând cercetări bazate pe date statistice la nivel de populație zonală.

Scopul cercetărilor este de a completa informațiile privind structura ecosistemelor de limită cu zâmbru din Carpați, bază științifică pentru fundamentarea măsurilor de management și conservare. Obiectul specific avut în vedere în cadrul prezentei lucrări este de caracterizare a structurii dendrometrice și calitative a populației de zâmbru de pe versantul nordic al Munților Călimani pe bază de inventariere extinsă.

\section{Material și metodă de lucru}

Zona de studiu este localizată pe versantul nordic al Munților Călimani (Carpații Orientali România) în cadrul Rezervației Jnepenișul cu Pinus cembra din Parcul Naţional Călimani (fig. 1). Vegetația lemnoasă este reprezentată de un amestec intim de molid (Picea abies (L.) Karst.) și zâmbru (Pinus cembra L.), cu exemplare diseminate de scoruș (Sorbus aucuparia L.) și salcie căprească de munte (Salix silesiaca L.). Subarboretul este reprezentant, mai ales în zona de tranziție dintre pădure și rariștea de molid cu zâmbru, de jneapăn (Pinus mugo Turra) și ienupăr (Juniperus communis Thunb), iar pe văi de anin verde (Alnus viridis Chaix DC).

După clasificarea românească a habitatelor (Doniță et al. 2005), zona de studiu este dominată de tipul de habitat R4202 Rariști sudest carpatice de molid (Picea abies) și zâmbru (Pinus cembra) cu Rhododendron myrtifollium, iar conform Directivei Habitate în această zonă predomină tipul de habitat 9420 Păduri de Larix decidua şi/sau Pinus cembra din regiunea montană. Climatul este specific zonei montane înalte cu o temperatură medie anuală de $8^{\circ} \mathrm{C}$ și un nivel anual al precipitațiilor care depășește $1200 \mathrm{~mm}$.

Arboretele cuprinse în cadrul rezervatiei au fost protejate începând cu anul 1971, extragerile de arborii fiind restricționate, cu mici excep- 


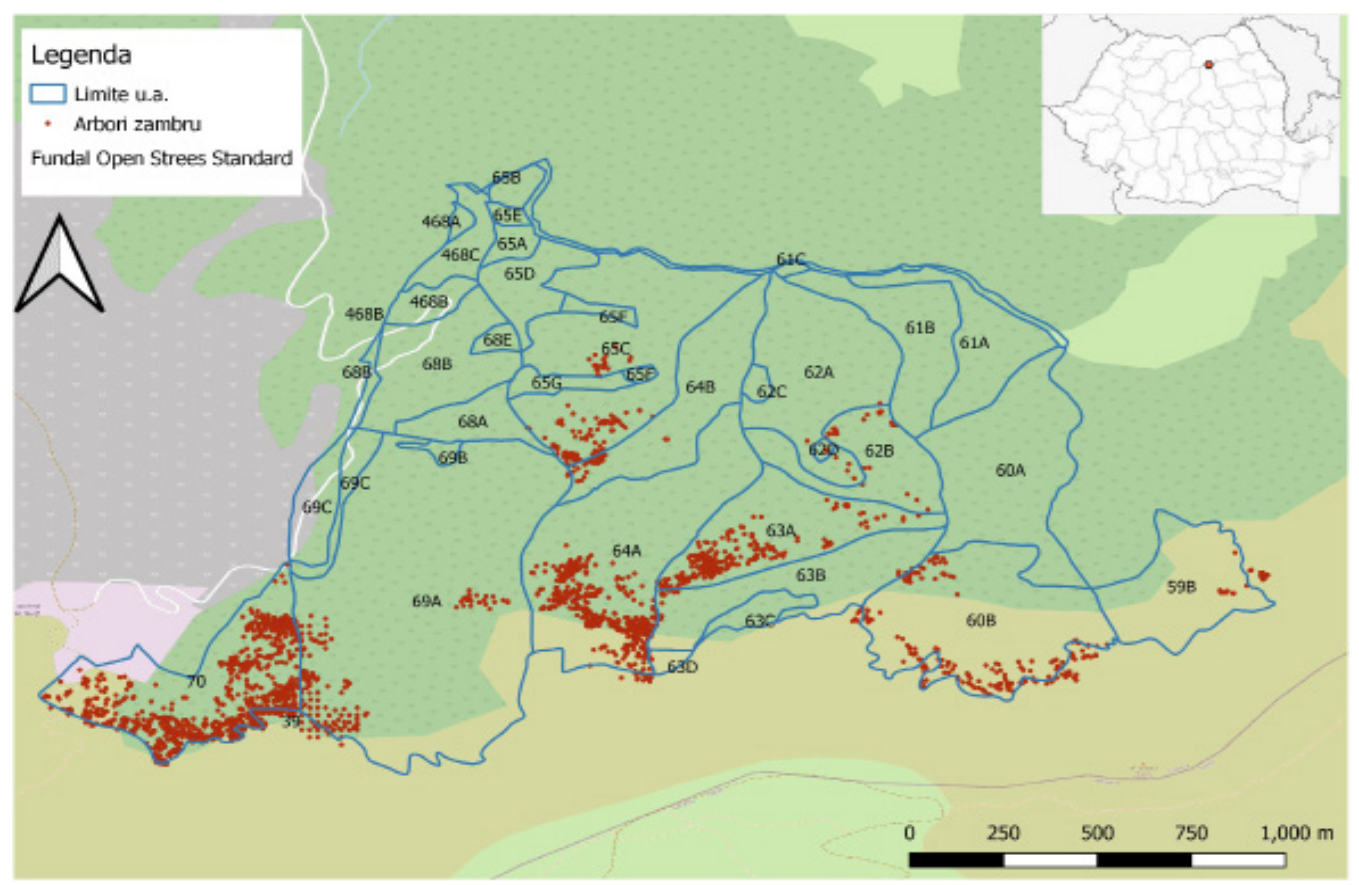

Figura 1 Localizarea zonei de inventariere a populației de zâmbru în cadrul Rezervației jnepeniș cu Pinus cembra - Călimani

Location of the stone pine population inventory area within the Reserve Jnepenis cu Pinus cembra-Calimani Mts.

ții în anul 1999 și 2001. Intervențiile punctuale efectuate în cadrul rezervației au fost limitate la extragerea unor atacuri de insecte, arborii exploatații fiind reprezentați de molid, fără impact asupra populaţiei de zâmbru. În apropierea rezervației a funcționat până în anul 1995 exploatarea de suprafață de sulf care a avut un impact negativ asupra ecosistemelor din jur prin poluarea în special cu pulberi solide.

Din suprafața totală a rezervației de 384,2 ha s-a realizat inventarierea integrală a populației de arbori de zâmbru pe o suprafaţă de 90 de ha, în perioada 2015-2019. Din populația totală de zâmbru din Munții Călimani, estimată la peste 7000 de exemplare de zâmbru (Seghedin 1983), s-au inventariat un număr total de 2869 arbori vii și 28 arbori morți pe picior (fig. 1). Exemplarele identificate au fost marcate cu plăcuțe înseriate pentru o recunoaștere ulterioară.

În teren, pentru fiecare exemplar de zâmbru cu diametrul de bază mai mare de 2 cm la înăl- țimea de 1,30 m s-au înregistrat următoarele elemente: localizarea spațială cu ajutorului unui GPS și diametrul de bază $(\mathrm{cm})$ cu ajutorul clupei sau a unei rulete în cazul arborilor cu diametre peste $100 \mathrm{~cm}$. Pentru caracterizarea calitativă a populației de arbori de zâmbru inventariată, s-au înregistrat pentru fiecare arbore următoarele elemente: starea de sănătate (sănătos - sub 10\% ramuri uscate în coroană; declin ușor - ramuri uscate în coroană între 11 și $50 \%$; declin sever - peste $50 \%$ din coroană uscată), prezența vătămărilor și tipul acestora $(\mathrm{CP}$ - ciuperci cu corpi fructiferi, $\mathrm{RD}$ - răni deschise, RI - răni închise, CA - ulceraţii, cancere, IN - vătămări insecte, MA - vătămări mamifere, AN - vătămări antropice, FV - fără vătămări), respectiv localizarea lor (partea de jos a trunchiului - la o înălţimea mai mică de 1/3 din înălţimea totală; partea de sus - la o înălțimea mai mare decât $1 / 3$ din înălțimea totală; pe tot trunchiul). De asemenea s-au înre- 


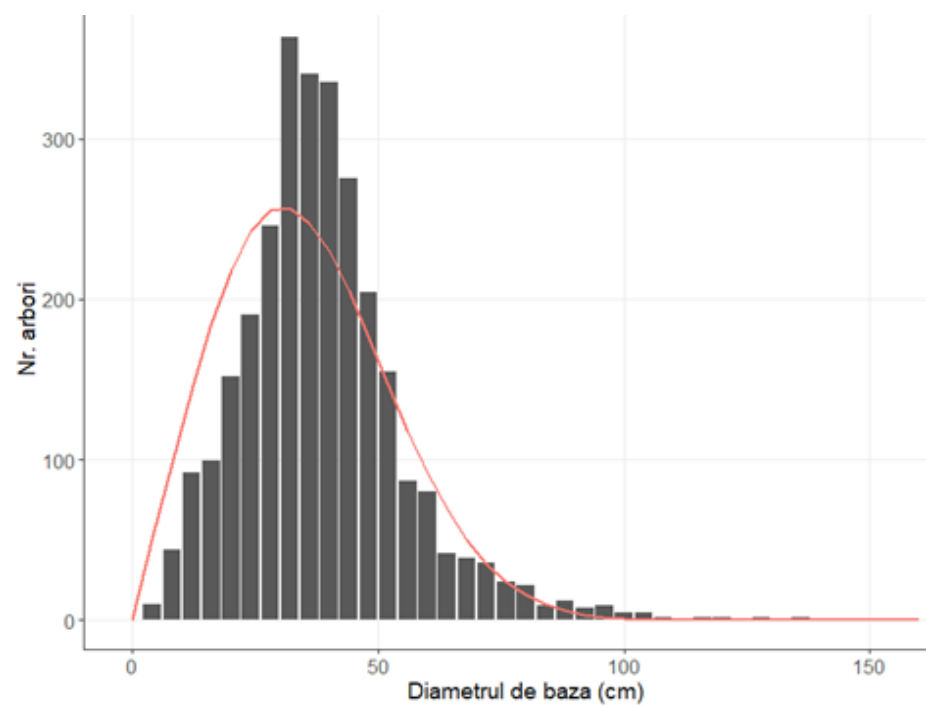

Figura 2 Distribuția numărului de arbori de zâmbru pe categorii de diametre modelată cu funcția de repartiție Weibull Distribution of the number of stone pine trees by diameter classes modeled with Weilbull function gistrat informații suplimentare, în cazul în care a fost posibil, privind agentul vătămător (ciocănitori, urs, cervide etc.).

Informațiile cantitative și calitative înregistrate în teren au fost verificate și validate corectându-se erorile de înregistrare. Caracterizarea dendrometrică a populației de zâmbru de pe versantul nordic al Munților Călimani s-a realizat prin intermediul indicatorilor statistici (medie, abatere standard și coeficient de variaţie) şi a distribuției arborilor în raport cu diametrul de bază modelată cu funcția de repartiție teoretică Weilbull. Din punct de vedere calitativ analiza statistică s-a realizat prin intermediul distribuției numărului de arbori pe tipuri de vătămare și prin prisma stării de vegetaţie.

Prelucrarea statistică a informațiilor de teren s-a realizat prin programarea de rutine informatice specifice în programul de analiză statistică R (R Core Team 2017).

\section{Rezultate și discuții}

Populaţia de zâmbru de pe versantul nordic al Munților Călimani inventariată în cadrul acestui studiu cuprinde un număr de 2897 de exemplare distribuite în cuprinsul Rezervației jnepeniş cu Pinus cembra din Călimani cu o densitate de 32 exemplare/ha.

Din punct de vedere al diametrului de bază valoarea maximă înregistrată este de $156 \mathrm{~cm}$, cu o medie de $37,2 \pm 17,1 \mathrm{~cm}$ și un coeficient de variație $(\mathrm{CV})$ de $46 \%$. Cercetări anterioare efectuate în suprafețe de cercetare permanente localizate tot pe versantul nordic relevă caracteristici dendrometrice relativ similare (Sidor et al. 2013 - diametrul mediu 34,2 $\pm 10,2 \mathrm{~cm}$, CV - 29,8\%; Popa et al. $2017-36,2 \pm 19,6 \mathrm{~cm}$, CV - 54,1\%; Vlad et al. $2013-31,6 \pm 19,3 \mathrm{~m}$, CV - 61,1\%, Cenușă 1996 - 32,8-35,5 cm cu CV - 37,2-38,9\%). Vlad et al. (2013) raportează un diametru de bază maxim pentru zâmbru de 83,2 cm, Popa et al. (2017) un diametru maxim inventariat în suprafețele de probă permanente de $102 \mathrm{~cm}$, iar pentru versantul sudic Abran (2000) înregistrează un diametru maxim de $116 \mathrm{~cm}$.

Distribuția numărului de arbori pe categorii de diametre prezintă o ușoară asimetrie de stânga, fiind similară unei distribuții specifice arboretelor echiene, cu diametrul median de 36 cm (fig. 2). Pe categorii de grosime, exemplare de zâmbru inventariate se distribuie astfel: arbori subțiri (S) cu diametrul de bază mai mic de $25 \mathrm{~cm}-667$ arbori $(22,3 \%)$, arbori cu dimensiuni mijlocii (M) cu diametrul de bază cuprins între 25,1 şi 45,0 cm - 1479 arbori $(51,1 \%)$, 


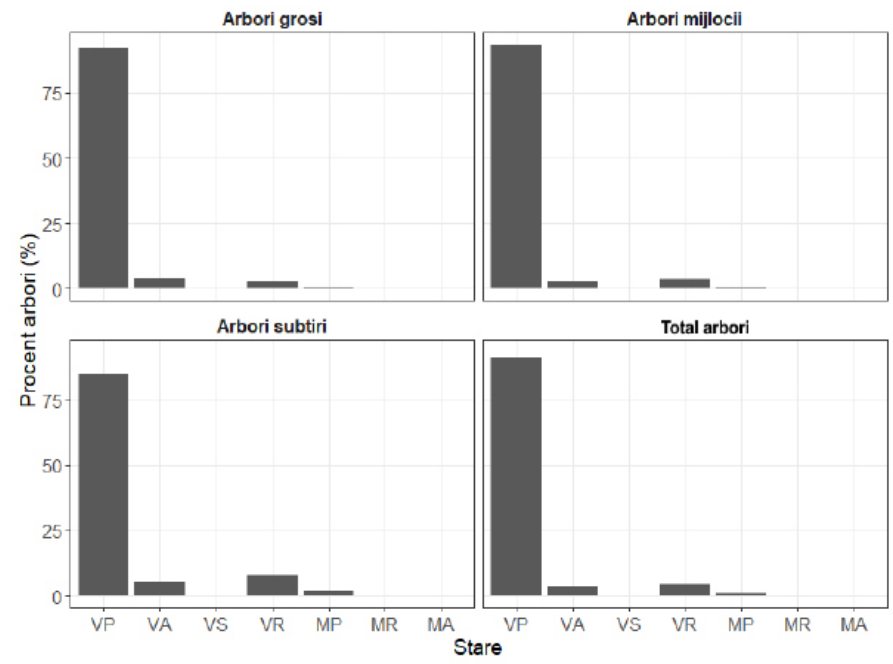

Figura 3 Distribuția exemplarelor de zâmbru în raport cu starea de vegetaţie (VP - viu pe picior, VA - viu aplecat, VS - viu la sol, VR - viu cu vârful rupt, MP - mort pe picior, MR - mort și rupt, MA - mort și aplecat) Distribution of stone pine trees by vegetation status categories (VP - live standing tree, $V A$ - live and bent, $V S$ - live on the ground, VR live with broken top, MP - dead standing tree, $M R$ - dead and broken, MA dead and bent)

respectiv arbori groși cu diametrul mai mare de 45,0 cm - 751 arbori $(26,6 \%)$. O formă similară a distribuției numărului de arbori pe categorii de diametre pentru zâmbru s-a observat şi în suprafețele de cercetare permanente din Munții Călimani, diferită de cea constatată în cazul molidului (tipică arboretelor pluriene sau relativ pluriene) (Popa et al. 2017, Vlad et al. 2013).

Ponderea arborilor morți pe picior este redusă (28 arbori - 1,0\%), majoritatea fiind arbori subțiri (14 exemplare), vătămați foarte puternic de urs sau cervide prin distrugerea cojii pe toată circumferința trunchiului. În cazul zonei de studiu lemnul mort provenit din arborii de zâmbru este preponderent lemn mort la sol, cu o rată de degradare în timp foarte lentă, de ordinul sutelor de ani, fiind centrii de biodiversitate extrem de importanţi (Popa 2007, Popa şi Kern 2009).

Se remarcă o pondere relativ ridicată a arborilor vii cu vârful rupt (4,4\%), refăcut sau nu, respectiv a arborilor vii cu trunchiul aplecat sub diferite unghiuri $(3,6 \%)$, distribuţia acestora pe categorii de grosime fiind similară (fig. 3). Incidența rupturilor de vârf urmare a acțiunii mecanice a zăpezii la arborii de zâmbru este mult mai redusă comparativ cu molidul, datorită flexibilității mai ridicate a lemnului
(Wieser și Tausz 2007).

Din punct de vedere al stării de sănătate se observă faptul că majoritatea arborilor de zâmbru sunt sănătoși $(90,2 \%)$. Proporția arborilor în declin ușor și sever este mai mare în cazul exemplarelor subțiri $(16,9 \%)$ comparativ cu celelalte categorii de grosime. Totuși, în cadrul populației analizate, ponderea arborilor cu declin fiziologic este redusă (8,8\%) (fig. 4).

Majoritatea arborilor de zâmbru inventariați nu prezintă vătămări vizibile $(83,3 \%)$. Proporția arborilor fără vătămări este mai redusă în cazul exemplarelor cu diametre mari $(67,6 \%)$ comparativ cu arborii subțiri sau mijlocii (fig. 5). În ceea ce privește tipurile de vătămări observate la arborii de zâmbru inventariați, majoritatea se referă la prezența rănilor deschise $(5,7 \%)$ sau închise $(8,4 \%)$ pe trunchi, provocate de factori biotici (urs, cervide), abiotici (trăsnet, gelivuri) sau antropici. Ponderea cumulată a rănilor (deschise sau închise) în raport cu categoriile de grosime ale arborilor, creștere de la 9,7\% în cazul arborilor subțiri, la $27,0 \%$ în cazul arborilor groșii, fiind de 9,4\% la arborii mijlocii.

Majoritatea vătămărilor observate sunt localizate în partea inferioară a trunchiului (S - 84,2\%, M - 86,3\%, G - 87,8\%), proporția celor observate în partea superioară a trunchiu- 

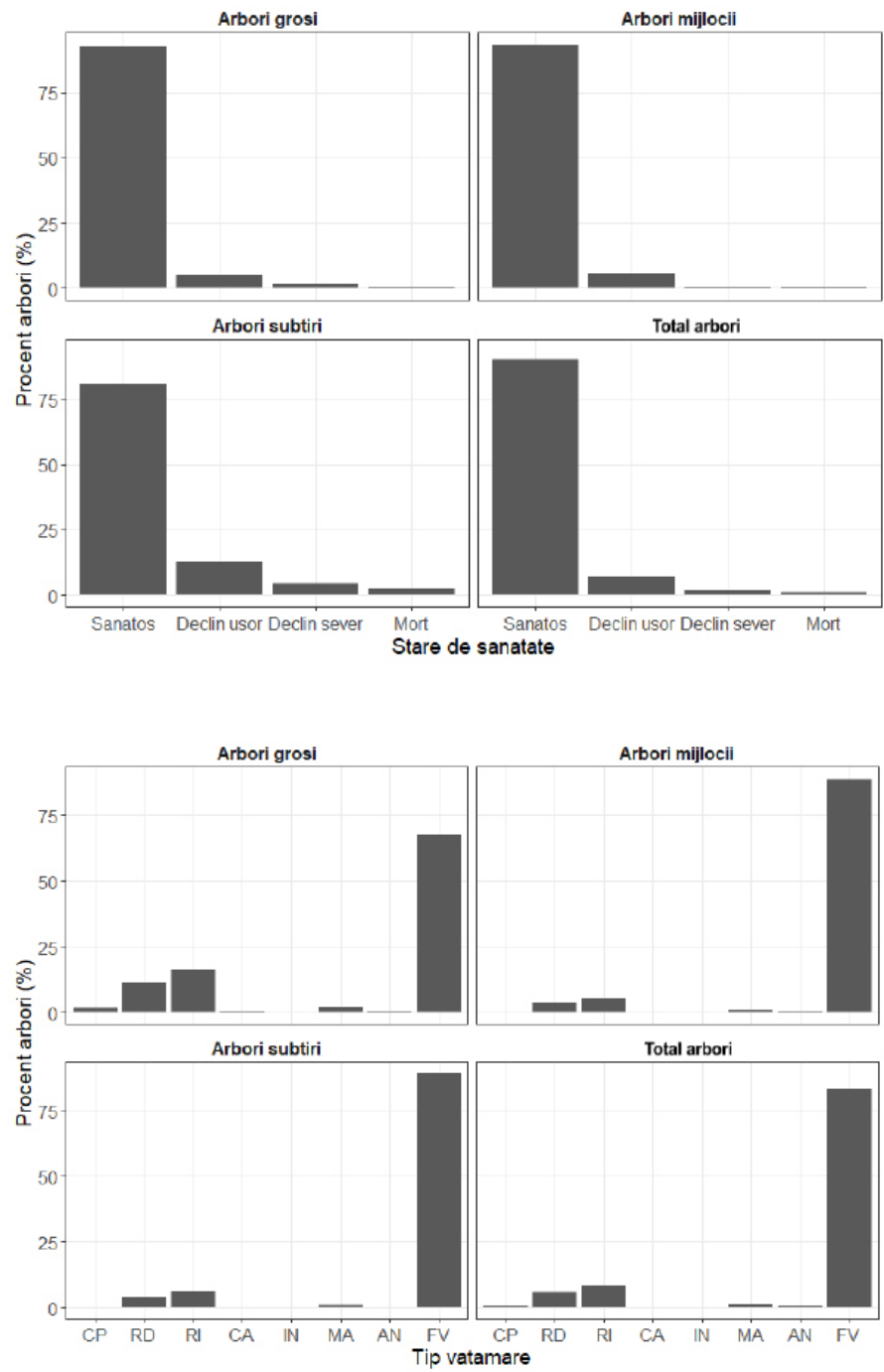

Figura 4 Distribuția arborilor de zâmbru în raport cu starea de sănătate

Distribution of trees by health categories

Distribuția arborilor de zâmbru în raportul cu tipul vătămării $(\mathrm{CP}$ - ciuperci cu corpi fructiferi, RD - răni Figura 5 deschise, RI - răni închise, $\mathrm{CA}$ - ulcerații, cancere, IN vătămări insecte, MA - vătămări mamifere, AN - vătămări antropice, FV - fără vătămări)

Distribution of stone pine trees by damage types (CP - fungi with fruiting bodies, $R d$ - open wounds, RI - closed wounds, CA - ulcers, cancers, IN - insect damage, MA - mammals damage, $A N$ - anthropogenic injuries, $P V$ - without damages) lui fiind redusă (6,7\%). Vătămările produse de insecte sunt reduse (20 arbori), majoritatea fiind mai vechi de 5 ani. Referitor la vătămările produse de mamifere, în special de urs şi cervide, $88 \%$ din acestea sunt vătămări vechi.

Vătămări produse de ciocănitori, respectiv găuri specifice, s-au identificat la un număr de 79 exemplare (2,7\%), 69 arbori având găurile la baza trunchiului, respectiv 10 exemplare la o înălțime mai mare de $1 / 3$ din înălțimea totală a arborilor m. Prezența arborilor cu găuri de ciocănitori reprezintă un indicator de biodi- versitate important în evaluarea stării de conservare a ecosistemelor forestiere din zona de studiu.

Inventarierile efectuate au evidențiat o pondere mai mare a proporției zâmbrului în partea altitudinală superioară a rezervației, respectiv în zona de tranziţie către tufărișurile cu jneapăn din păşunea alpină Răchitiş, constituind aici rarişti distincte. Prezența arborilor tineri de zâmbru, cu diametre mici, indică faptul că regenerarea naturală se produce în condiții relativ bune, iar dinamica populaţiei de zâmbru 
din zona de studiu este favorabilă. Studii de dendroecologie efectuate în zona de studiu relevă o creștere în ultimele decenii a proporției exemplarelor de zâmbru, dar şi de molid, în zona de tranziție între pădurea compactă și rariștile dominate de jneapăn (Popa et al. 2017). În ultimele decenii s-a constatat la nivel european o creștere a frecvenței simptomelor de declin fiziologic pe fondul poluării cu ozon și a schimbărilor climatice, mai ales în zona Alpilor Maritimi și Carpați, cu impact asupra stabilității habitatelor cu zâmbru (Wieser et al. 2006). Modelele de simulare prognozează pentru zona Carpatică o creștere a zonelor favorabile în următorul deceniu la altitudini mari, urmată de o reducere semnificativă după anul 2050, respectiv de dispariția completă a zonelor favorabile pentru zâmbru în 2080 (Casalegno et al. 2010).

\section{Concluzii}

Prezentul studiu reprezintă prima inventariere extinsă (2897 arbori inventariați) a populației de zâmbru de pe versantul nordic al Munților Călimani, oferind informații cantitative și calitative privind structura și starea de vegetaţie a acesteia. Observațiile și analizele statistice realizate reflectă o stare de vegetație foarte bună a exemplarelor de zâmbru din Munții Călimani și un structură în raport cu diametrul de bază echilibrată. Majoritatea arborilor inventariaţi au o stare de sănătate bună $(90,2 \%)$, fiind lipsiți de vătămări semnificative. Ponderea cea mai mare a vătămărilor observate sunt de tipul rănilor închise sau deschise, fiind prezente la peste 14\% din arborii de zâmbru inventariați. Prezența la 2,7\% (79 exemplare) dintre arborii de zâmbri inventariați a găurilor produse de ciocănitori coroborat cu identificarea unor arbori cu diametre de peste $100 \mathrm{~cm}$ reprezintă un indicator al biodiversității ridicate în ecosistemele forestiere de limită pe de versantul nordic al Munților Călimani.

Continuarea investigațiilor privind structura populaţiei de zâmbru pe tot cuprinsul Parcului
Național Călimani va permite obținerea de informații complete privind starea actuală a populației, informații esenţiale în fundamentarea măsurile de management necesare pentru asigurarea stării de conservare optime.

\section{Bibliografie}

Abran P., 2000. Cercetări privind prezența zâmbrului (Pinus cembra L.) pe versantul sudic al Munților Călimani, în județul Mureș. Revista Pădurilor. 2:13-15.

Beloiu M., Beierkuhnlein, C., 2019. Differences in the Spatial Structure of Two Pinus cembra L. Populations in the Carpathian Mountains. Forests, 10(4):326. https://doi.org/10.3390/f10040326

Blada I., 1997. Stone pine (Pinus cembra L.) provenance experiment in Romania. Silvae Genetica, 46(4):197200.

Blada I., 2008. Pinus cembra distribution in the Romanian Carpathians. Ann. For. Res. 51: 115-132.

Carrer M., Nola P., Eduard J.L., Motta R., Urbinati C., 2007. Regional variability of climate-growth relationships in Pinus cembra high elevation forests in the Alps. Journal of Ecology. 95(5):1072-1083. https://doi. org/10.1111/j.1365-2745.2007.01281.x

Carrer M., Soraruf L., Lingua, E., 2013. Convergent space-time tree regeneration patterns along an elevation gradient at high altitude in the Alps. Forest ecology and management. 304:1-9. https://doi.org/10.1016/j.foreco.2013.04.025

Carrer M., Urbinati C., 2001. Spatial analysis of structural and tree-ring related parameters in a timberline forest in the Italian Alps. Journal of Vegetation Science, 12(5):643-652. https://doi.org/10.2307/3236904

Casalegno S., Amatulli G., Camia A., Nelson A., Pekkarinen A., 2010. Vulnerability of Pinus cembra L. in the Alps and the Carpathian mountains under present and future climates. Forest Ecology and Management. 259(4):750-761. https://doi.org/10.1016/j.foreco.2009.10.001

Cenuşă R., 1996. Probleme de ecologie forestieră - Aplicaţii la molidişuri naturale din Bucovina. Universitatea din Suceava. Facultatea de silvicultură. 165 p.

Doniță N., Paucă-Comănescu M., Popescu A., Mihăilescu S., Biriş I. A., 2005. Habitatele din România. Bucureşti. Editura Tehnică Silvică.

Gubesh L.,1971. Răspândirea relictului glaciar zâmbrul (Pinus cembra) pe versanții sudici ai unor masive din Călimani. Ocrotirea Naturii. 15(2):149-159.

Kern Z., Popa I., 2008. Changes of frost damage and treeline advance for swiss Stone Pine in the Calimani Mts. (Eastern Carpathians, Romania). Acta Silvatica et Lignaria Hungarica. 4:39-48.

Lingua E., Cherubini P., Motta R., Nola P., 2008. Spatial structure along an altitudinal gradient in the Italian cen- 
tral Alps suggests competition and facilitation among coniferous species. Journal of Vegetation Science, 19(3):425-436. https://doi.org/10.3170/2008-8-18391

Motta R., Morales M., Nola P., 2006. Human land-use, forest dynamics and tree growth at the treeline in the western italian alps. Annals of Forest Science 63:739747. https://doi.org/10.1051/forest:2006055

Nagavciuc V., Kern Z., Ionita M., Hartl C., Konter O., Esper J., Popa, I., 2020. Climate signals in carbon and oxygen isotope ratios of Pinus cembra tree-ring cellulose from the Călimani Mountains, Romania. International Journal of Climatology. 40(5):2539-2556. https:// doi.org/10.1002/joc.6349

Oberhuber W., 2004. Influence of climate on radial growth of Pinus cembra within the alpine timberline ecotone. Tree physiology. 24(3):291-301. https://doi. org/10.1093/treephys/24.3.291

Popa I., 2007. Şapte secole de istorie auxologicã a unui Zâmbru (Pinus cembra L.). Revista Pădurilor. 5:18-23.

Popa I., Bouriaud O., 2014. Reconstruction of summer temperatures in Eastern Carpathian Mountains (Rodna Mts, Romania) back to AD 1460 from tree-rings. International Journal of Climatology, 34(3):871-880. https:// doi.org/10.1002/joc.3730

Popa I., Kern Z., 2009. Long-term summer temperature reconstruction inferred from tree-ring records from the Eastern Carpathians. Climate dynamics. 32(7-8):11071117. https://doi.org/10.1007/s00382-008-0439-x

Popa I., Nechita C., Hofgaard A., 2017. Stand structure, recruitment and growth dynamics in mixed subalpine spruce and Swiss stone pine forests in the Eastern Carpathians. Science of the Total Environment. 598:1050-
1057. https://doi.org/10.1016/j.scitotenv.2017.04.169

Popa, I., Popa, C., 2007, Impactul modificărilor structurale asupra proceselor auxologice într-un ecosistem de limită cu molid (Picea abies Karst) și zâmbru (Pinus cembra L.) din Munții Rodnei, Revista pădurilor, 2:10-18.

R Core Team, 2017. R: A language and environment for statistical computing. R Foundation for Statistical Computing, Vienna, Austria.

Seghedin T., 1983. Rezervațiile naturale din Bucovina. Ed. Sport și turism, București.

Sidor C.G., Popa I., Vlad R., 2013. Spatial structure of spruce-stone pine mixed forest from Calimani Mountains (Eastern Carpathians). Advances in Environmental Sciences. 5(3):328-333.

Ulber M., Gugerli F., Bozi G., 2004. EUFORGEN Technical Guidelines for Genetic Conservation and Use of Swiss Stone Pine (Pinus cembra L.). International Plant Genetic Resources Institute, Rome, Italy. 6 p.

Vlad R., Popa I., Sidor C., Nechita C., 2013. High mountain forest structure in Călimani Mts.(Eastern Carpathians). Analele Universității din Oradea, Fascicula: Protecția Mediului. 20:179-186.

Wieser G., Manning W.J., Tausz M., Bytnerowicz A., 2006. Evidence for potential impacts of ozone on Pinus cembra L. at mountain sites in Europe: An overview. Environmental Pollution. 139(1):53-58. https://doi.org/10.1016/j.envpol.2005.04.037

Wieser G., Tausz M., 2007. Trees at their upper limit: treelife limitation at the alpine timberline. Springer Science and Business Media. 232 p. https://doi.org/10.1007/14020-5074-7 